\title{
ON SEMIMONOTONE STAR MATRICES AND LINEAR COMPLEMENTARITY PROBLEM
}

\author{
R. JANA*, A. K. DAS, S. SINHA
}

Abstract. In this article, we introduce the class of semimonotone star $\left(E_{0}^{s}\right)$ matrices. We establish the importance of the class of $E_{0}^{s}$-matrices in the context of complementarity theory. We show that the principal pivot transform of an $E_{0}^{s}$-matrix is not necessarily $E_{0}^{s}$ in general. However, we prove that $\tilde{E}_{0}^{s}$-matrices, a subclass of the $E_{0}^{s}$-matrices with some additional conditions, is fully semimonotone matrix by showing this class is in $P_{0}$. We prove that $\operatorname{LCP}(q, A)$ can be processable by Lemke's algorithm if $A \in \tilde{E}_{0}^{s} \cap P_{0}$. We find some conditions for which the solution set of $\operatorname{LCP}(q, A)$ is bounded and stable under the $\tilde{E}_{0}^{s}$-property. We propose an algorithm based on an interior point method to solve $\operatorname{LCP}(q, A)$ given $A \in \tilde{E}_{0}^{s}$.

Mathematics subject classification (2020): 90C33, 90C90, 15B99.

Keywords and phrases: Linear complementarity problem, principal pivot transform, Lemke's algorithm, interior point method, semimonotone star matrix, $\tilde{E}_{0}^{S}$-matrix.

\section{REFERENCES}

[1] Ilan Adler, Richard W. Cottle And Sushil Verma, Sufficient matrices belong to L, Mathematical Programming 106 (2) (2006), pp. 391-401.

[2] M. Aganagic And R. W. Cottle, A constructive characterization of $Q_{0}$-matrices with nonnegative principal minors, Mathematical Programming, 37 (2) (1987), pp. 223-231.

[3] M. CAO AND M. C. FERRIS, $P_{c}$-matrices and the linear complementarity problem, Linear Algebra and its Applications, 246 (1996), pp. 299-312.

[4] T. H. CHU, On semimonotone matrices with nonnegative principal minors, Linear algebra and its applications, 367 (2003), pp. 147-154.

[5] RichaRd W. COTtLE, A field guide to the matrix classes found in the literature of the linear complementarity problem, Journal of Global Optimization 46 (4) (2010), pp. 571-580.

[6] R. W. CotTLE, The principal pivoting method revisited, Mathematical Programming, 48 (1) (1990), pp. 369-385.

[7] R. W. Cottle And S. M. GuU, Two characterizations of sufficient matrices, Linear algebra and its applications, 170 (1992), pp. 65-74.

[8] R. W. Cottle, J. S. Pang and R. E. Stone, The linear complementarity problem, Society for Industrial and Applied Mathematics, 2009.

[9] Richard W. Cottle ANd Richard E. Stone, On the uniqueness of solutions to linear complementarity problems, Mathematical Programming 27 (2) (1983), pp. 191-213.

[10] A. K. DAS, Properties of some matrix classes based on principal pivot transform, Annals of Operations Research, 243 (1-2) (2016), pp. 375-382.

[11] A. K. Das, R. Jana And Deepmala, On Generalized Positive Subdefinite Matrices and Interior Point Algorithm, International Conference on Frontiers in Optimization: Theory and Applications, pp. 3-16, 2016.

[12] B. C. EAVES, The linear complementarity problem, Management science, 17 (9) (1971), pp. 612-634.

[13] F. Flores-BAZÁn AND R. LóPEZ, Characterizing Q-matrices beyond L-matrices, Journal of optimization theory and applications, 127 (2) (2005), pp. 447-457.

[14] M. S. GowDA, Pseudomonotone and copositive star matrices, Linear Algebra and Its Applications, 113 (1989), pp. 107-118. 
[15] M. S. Gowda AND J. S. PANG, On solution stability of the linear complementarity problem, Mathematics of Operations Research, 17 (1) (1992), pp. 77-83.

[16] R. Jana, A. K. Das And S. Sinha, On Processability of Lemke's Algorithm, Applications \& Applied Mathematics 13 (2) (2018), pp. 1123-1131.

[17] C. Jones AND M. S. GowdA, On the connectedness of solution sets in linear complementarity problems, Linear algebra and its applications, 272 (1-3) (1998), pp. 33-44.

[18] Masakazu Kojima, Nimrod Megiddo, Toshinito Noma, and Akiko Yoshise, A unified approach to interior point algorithms for linear complementarity problems, Springer Science \& Business Media 538 (1991).

[19] S. R. Mohan, S. K. Neogy and A. K. Das, More on positive subdefinite matrices and the linear complementarity problem, Linear Algebra and its Applications 338 (1-3) (2001), pp. 275-285.

[20] S. R. Mohan, S. K. NeOgY AND A. K. DAS, On the classes of fully copositive and fully semimonotone matrices, Linear Algebra and its Applications 323 (1-3) (2001), pp. 87-97.

[21] G. S. R. Murthy and T. Parthasarathy, Some Properties of Fully Semimonotone, $Q_{0}$ Matrices, SIAM Journal on Matrix Analysis and Applications 16 (4) (1995), pp. 1268-1286.

[22] S. K. NeOgY And A. K. DAs, On almost type classes of matrices with Q-property, Linear and Multilinear Algebra 53 (4) (2005), pp. 243-257.

[23] S. K. NeOGY AND A. K. DAS, Principal pivot transforms of some classes of matrices, Linear algebra and its applications 400 (2005), pp. 243-252.

[24] S. K. NeOgY AND A. K. DAS, Some properties of generalized positive subdefinite matrices, SIAM journal on matrix analysis and applications 27 (4) (2006), pp. 988-995.

[25] S. K. Neogy, A. K. Das And AbhiJit Gupta, Generalized principal pivot transforms, complementarity theory and their applications in stochastic games, Optimization Letters 6 (2) (2012), pp. 339-356.

[26] J. S. PANG, Iterative descent algorithms for a row sufficient linear complementarity problem, SIAM journal on matrix analysis and applications, 12 (4) (1991), pp. 611-624.

[27] T. ParthaSARAThy AND B. SRIPARna, On the solution sets of linear complementarity problems, SIAM Journal on Matrix Analysis and Applications, 21 (4) (2000), pp. 1229-1235.

[28] M. J. TODD AND Y. YE, A centered projective algorithm for linear programming, Mathematics of Operations Research, 15 (3) (1990), pp. 508-529.

[29] Michael J. Tsatsomeros and Megan Wendler, Semimonotone Matrices, Linear Algebra and its Applications, 2019.

[30] H. VÄLIAHO, Almost copositive matrices, Linear Algebra and its applications, 116 (1989), pp. 121134.

[31] J. Von Neumann, A certain zero-sum two-person game equivalent to the optimal assignment problem, Contributions to the Theory of Games, 2 (1953), pp. 5-12.

[32] Wallace C. Pye, Almost $P_{0}$-matrices and the class $Q$, Mathematical programming 57 (1-3) (1992), pp. 439-444. 